\title{
Functional and dysfunctional urban mass transportation systems in the greater Gauteng region of South Africa
}

\author{
J. Chakwizira ${ }^{1}$, P. Bikam ${ }^{2}$ \& T. A. Adeboyejo ${ }^{1}$ \\ ${ }^{1}$ University of Venda, School of Environmental Sciences, \\ Thohoyandou, South Africa \\ ${ }^{2}$ Development Bank of Southern Africa, Midrand, South Africa
}

\begin{abstract}
The purpose of this article is to present some insights regarding functional and dysfunctional urban public mass transportation systems in the greater Gauteng region of South Africa. Making use of a case study approach that places greater Johannesburg and Pretoria region at the centre of the investigation, contextual urban public mass transport struggles and dialogues are reviewed. Employing the interview surveys and a synthesis approach, the capacity and capability of the existing urban public transport to meet expectations of the serviced population in the greater Johannesburg region is critiqued. The contribution and value add that recent improvements in public transport management such as the Gautrain and Rea Vaya Bus rapid Transit (BRT) are explored and urban public transport "pain points and hotspots" considered. The major conclusions of the paper revolve around implementing a package of innovative and alternative transport solutions and technologies to overcome various obstacles and constraints to improved public transport service and infrastructure delivery and sustainability.

Keywords: urban public transport, rapid transit systems, interventions, greater Gauteng region, South Africa.
\end{abstract}

\section{Introduction}

This article presents some insights regarding functional and dysfunctional urban public transportation systems in the greater Gauteng region (GGR). The study is motivated by multiple imperatives whose justification is embedded in current 
shortcomings and weaknesses inherent in the existing urban public transportation system and network of the greater Johannesburg region.

Firstly, the urban public transportation landscape field in South Africa just like elsewhere has been conceptualized from different angles. Consequently, different methods have been harnessed in generating solutions (Thomlinson et al. [1]). Secondly, the consequences of different transport pathways conceptualization have lead to different but commonly enriching options for resolving urban public transport in South Africa in general and Johannesburg in particular (Department of Transport [2]). Thirdly, while Johannesburg metropolis is "well served" by some 259 kilometers of motorway incorporating two concentric loops, one of which leads directly into the CBD, this has not spared the region from urban public transport problems such as congestion, long travelling hours to and from areas of socio-economic opportunity, traffic accidents, pollution and inefficient land use and transport integration among a host of other shortcomings. All this persists despite the existence of an approximately 240 kilometers of expressway (Beavon [3] 12).

Urban public transport planners and critics have questioned the functional efficiency of the existing urban transportation system and structure of the greater Johannesburg region (GJR) from two main perspectives, namely the traffic flow and the land integration dimension (Chakwizira [4]). This article therefore has as one of its aims challenging the functional capacity and ability of the existing transportation set-up to address greater Johannesburg $21^{\text {st }}$ century urban public transport problems in South Africa.

\subsection{Aim of article}

This article's aim is to interrogate the functional efficiency of the existing transport network and systems in the GJR with a view to generating innovative solutions that can address system and network performance gaps and or cracks. The broad objective of the article is attained through interrogating three discrete but complementary specific objectives, which are namely;

1. To map the urban public transportation system and network challenges in GJR.

2. To assess the potential impact that the Gautrain rapid rail link initiative will have in addressing contemporary urban public transportation system and network challenges in GJR.

3. To advance urban public transportation suggestions for enhanced system and network performance in the GJR.

\section{Research methods}

The study methodology relied on both qualitative and quantitative approaches. The unit of analysis is the GJR with case studies of Soweto, Soshanguve and Hammanskraal. Data collection techniques such as interviews with key role players, workshops and random sample interviews with public transport 
stakeholders (residents, commuters and public transport service providers) experiences were used. Overall, the research work was approached from a research and developmental perspective.

\section{Literature review}

The transport infrastructure and services supply paradigm argues that growth of cities and increase in traffic should be matched by a commensurate road expansion programme (Department of Transport [5]). On the contrary, transport infrastructure and services demand paradigm argues that no city in the world has resolved the problems of growth of cities and increase in traffic by constructing and building more roads, more freeways and highways (Chakwizira et al. [6]). Cities seeking to address contemporary urban transport problems may need to apply innovative solutions that strike a balance between traditional and neotraditional urban transport spectrum of interventions.

Overall, the perceived need for exercising autonomy over public transport service delivery has seen many cities around the world become innovative and effective transport transformation and change management agents. Cervero [7] identifies examples of four city archetypes that, through proper and dedicated transport planning and management, have been able to deliver sustainable public transport. Firstly, adaptive cities have invested in high capacity public transport systems i.e. rail, to guide urban growth. Examples are Copenhagen, Tokyo, and Stockholm (Wright [8]). Secondly, adaptive public transport cities have managed to successfully adapt their public transport to serve somewhat dysfunctional urban sprawls. Examples are Karlsruhe, Adelaide and Mexico City (ibid). Thirdly, strong core cities have successfully integrated public transport with the built environment within a more confined central city context. Examples are Zurich and Melbourne (Gwilliam [9]). Fourthly, hybrids combining adaptive cities and adaptive public transport archetypes are cities that have managed to concentrate their development around main public transport corridors and at the same time adapting the public transport system to serve outlying areas. Examples are Curitiba, Ottawa and Munich (Chakwizira et al. [6]).

Theories that explain and describe public transport infrastructure and services deployment, policy environment, commuter behaviour and outcomes exist. These are the classic transport monocentric model, linear public transport commuting minimising programming model, network equilibrium and stochastic route choice, gravity model and transport trip distribution, random utility models with network equilibrium approaches, urban transport network equilibrium, random utility, practitioner travel forecasting models and combined/integrated choice models have been implemented and operationalised with the aid of software systems (Wright [8]). These applications have had great influence and impact to urban transport planning and models application in South Africa. Despite all these models and transport technology applications being available for use in the GJR in particular and South Africa in general, the challenge of sustainable urban public transportation has not declined but instead since become much more sharply pronounced and requiring urgent priority than before. 


\subsection{Conceptual framework}

The development of this article required the application of a robust conceptual framework (refer to figure 1). The conceptual framework assisted in unlocking and dismantling key components of functional and dysfunctional urban mass transport in GJR. Defining key concepts that frame the boundaries of this article is important in providing a foundation for understanding the context and meaning by which such concepts and terms are used throughout this article. Functional urban mass transport is defined as constituting an urban mass transport systems that is (are) efficient, seamless, integrated, cost-effective, appropriate, reliable, consistent, sustainable and affordable (Wright [8]). Dysfunctional urban mass transport is defined as enveloping urban mass

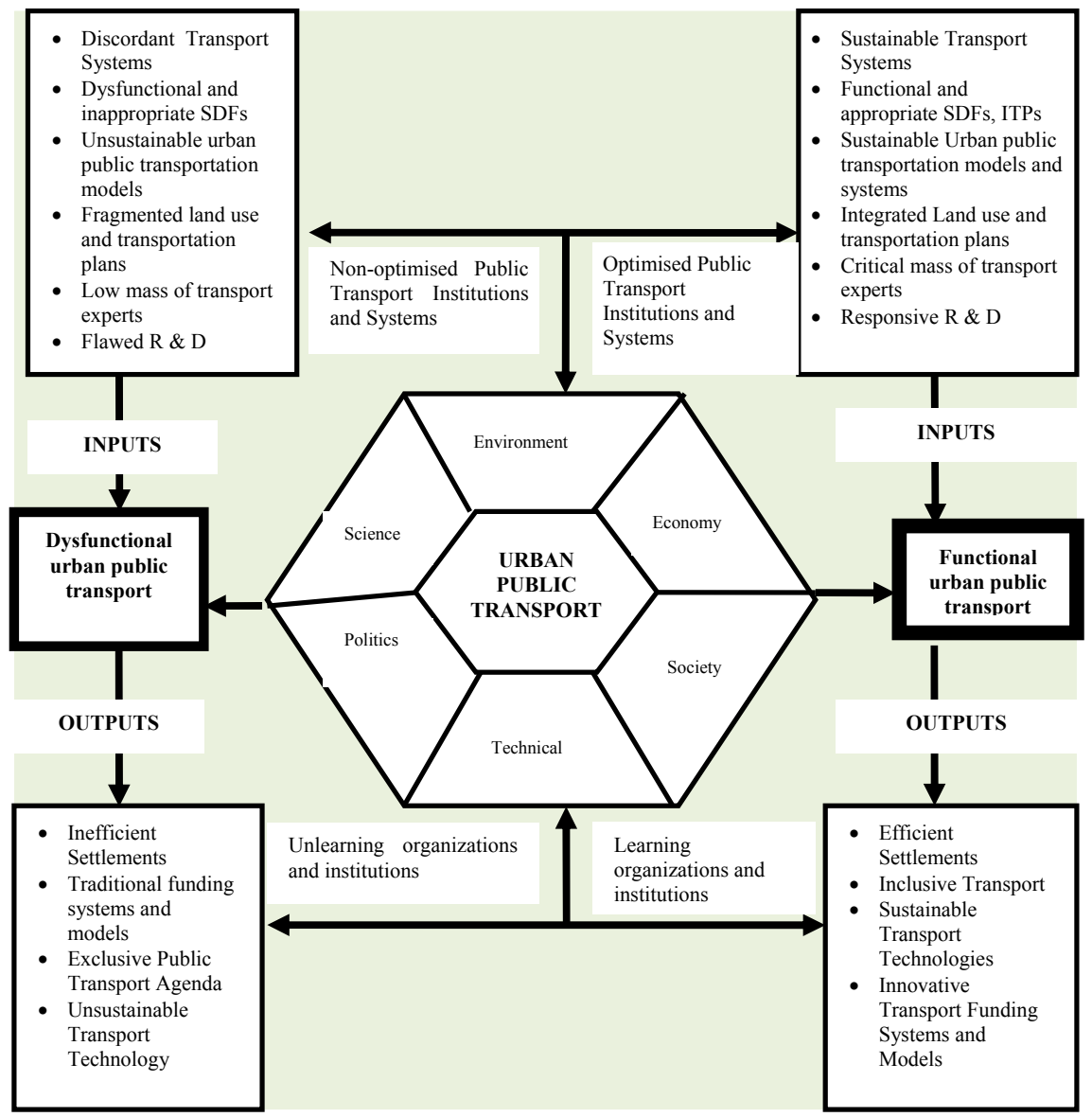

Source: Study Findings, 2009.

Figure 1: $\quad$ Schematic representation of the conceptual framework. 
transport that is inefficient, fragmented, disconnected, costly, inappropriate, inconsistent and not sustainable (Gwilliam [9]). Figure 1 overleaf presents the hexagonal factors that drive urban public transport mass transport. This article argues that a healthy application mix of these hexagonal factors yields positive and functional urban mass transport systems and network outcomes. On the contrary a flawed application mix of the same hexagonal factors produces a dysfunctional urban mass transport system and network outcome.

\section{Discussion of study findings and results}

This section presents the results from the research findings. The section discusses current challenges in public transport including a discussion of the Gautrain rapid rail link interventions to address these challenges in the GJR.

\subsection{Greater Johannesburg region public transport route and network system}

Johannesburg's public transit metro railway system connects central Johannesburg with Soweto, Pretoria and most of the satellite towns along the Witwatersrand, transporting huge volumes of workers every day. However, the railway system built during Johannesburg's infancy covers largely the older areas of the city, despite Johannesburg's growth largely northwards in the past 50 years, and none of the key districts of Sandton, Midrand, Ranburg and Rosebank have any meaningful rail infrastructure. It is in this context that the Gautrain rapid rail link has been proposed and is being implemented to relieve traffic congestion on the N1 freeway between Johannesburg and Pretoria, which records traffic loads of over 160000 per day (Wright [8]). Johannesburg is served by OR Tambo International Airport (Formerly Johannesburg International Airport). Other airports include Rand Airport, Grand Central Airport and Lanseria.

Johannesburg is not built near any large navigable rivers. This means that, from the beginning, ground transport has been a leading method of transporting people and goods in, around and beyond the GJR. Johannesburg ring/orbital road is comprised of three freeways that converge on the city. The N3 eastern bypass links Johannesburg with Pretoria town. The N12 southern bypass links Johannesburg with Witbank and Kimberley. It also consists of the busy N1 route already mentioned. The N3 was built with asphalt, while the N12 and N1 western bypass are constructed of concrete. In spite of being up to 12 lanes wide in some areas (6 lanes per one direction), the Johannesburg ring road is frequently congested with traffic.

Gauteng's road network has to cope with an annual traffic increase rate of $7 \%$, with 1.8 million drivers and 2.8 million registered vehicles (Department of Transport, 2008). 40\% of the national fleet and traffic has been increasing on the M1/N1 corridor, roughly $7 \%$ a year over the past 10 years. The average travel time to work in the Greater Johannesburg Area has increased from 41,5 minutes in 1995 to 50 minutes in 2003, representing a 17\% increase over eight years 
(Shaw [10]). Traffic congestion affects thousands of people daily in Gauteng Province. During the peak hours, the impact of accidents and the resulting delays add to the general navigation difficulties for road users. Central and local government have since adopted strategies and proposals to counter the everincreasing congestion on modern urban freeways and arterials, such as the Gauteng road improvement and upgrading programme, the tolling of the Gauteng arterial road network, high vehicle and occupancy lanes in the quest to optimise the use of existing infrastructure by means of technologically aided congestion management.

As a consequence the City of Johannesburg (CoJ), Integrated Transport Plan (ITP) aims at creating "a safe and efficient transportation system, with a public transport focus, that will support a world class City; connecting businesses, people and places in a sustainable and cost effective manner and through this, improve the standard of living and quality of life of all the City's inhabitants and the overall competitiveness and growth of the City's economy". Achieving such a feat requires more concerted and integrated efforts by all urban transport stakeholders. The road network within the CoJ area is estimated to comprise some 7500 kilometres of road. This is further subdivided into approximately 565 kilometres of freeway and approximately 1260 kilometres of main arterial roads. Consequently the bulk of the road network comprises tertiary roads which provide access to properties and link to the higher order routes (IDP, 2008). The remainder of the roads are under the Johannesburg Road Agency (JRA) and municipalities within the GJR such as Tshwane Metropolitan municipality and Ekurhuleni Metropolitan municipality.

While the question of promoting public transport seems compelling, observers have raised concern with how such a strategy will be pursued taking into account transport governance systems, the high car ownership patterns and trends in the GJR (Chakwizira and Mashiri [12]). Linking urban public transport initiatives including restraint measures such as the about to be implemented Gauteng freeway toll road system and sharpening spatial development frameworks in line with existing and envisaged mobility spines remains a growing challenge.

\subsection{Current urban public transport challenges in the greater Johannesburg region}

The urban public transport system in South Africa generally and GJR in particular faces many challenges. The apartheid city design policies crafted fragmented and functionally in-efficient cities and spaces (Donaldson [13]). Residential areas such as Soshanguve, Hammanskraal and Soweto (where car ownership is as low as $38 \%$ ) where the majority of public transport communities live are located far away from major industrial and commercial centres of Pretoria and Johannesburg respectively. While the middle and higher income earners in Pretoria East, Sandton, Midrand residential suburbs (where car ownership is as high as $82 \%$ ) can afford alternative urban transport means, the same cannot be said of captive urban public transport community members (Research Survey Findings, 2010). Table 1 presents the major urban public 
transport challenges faced by commuters in Soshanguve, Hammanskraal and Soweto during the study period. A limited purposive sample was adopted given that a census could not be done owing to time and budget constraints. Survey respondents from a limited purposive sample of randomised 300 residents from Soweto (100), Soshanguve (100) and Hammanskraal (100) conducted in 2010 expressed different levels of dissatisfaction with train, bus and taxi modes of transport (refer to table 1). These levels of dissatisfaction speaks to the dysfunctional dimensions of transport challenges experienced by the commuters, namely cost, long distances from pick-up and drop off points, fragmentation of socio-economic opportunities, crime and violence. Improvements in bus services and train services are critical. The Bus Rapid Transit (BRT) and Gautrain rapid rail link initiative should seek to reverse urban public transport dysfunctional challenges through seeking to exceed public transport customer service expectations.

In addition, as a consequence of the existing fragmented and dysfunctional spatial land use and transport system middle and high income locations residents

Table 1: $\quad$ Study findings of major urban public transport problems faced by commuters in Soshanguve, Hammanskraal and Soweto.

Sample Size N=300

\begin{tabular}{|c|c|c|c|c|c|c|c|c|c|}
\hline & \multicolumn{3}{|c|}{ Soweto } & \multicolumn{3}{|c|}{ Soshanguve } & \multicolumn{3}{|c|}{ "Hammanskraal } \\
\hline 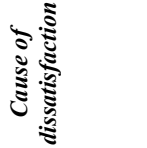 & 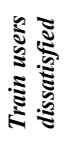 & 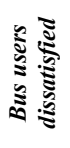 & 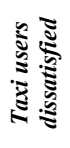 & 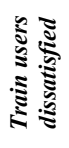 & 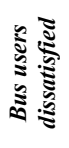 & 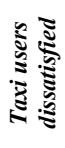 & 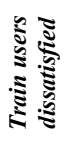 & 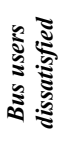 & 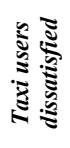 \\
\hline Cost & $20 \%$ & $32 \%$ & $48 \%$ & $16 \%$ & $36 \%$ & $48 \%$ & $13 \%$ & $39 \%$ & $48 \%$ \\
\hline $\begin{array}{c}\text { Distance } \\
\text { from home }\end{array}$ & $48 \%$ & $30 \%$ & $22 \%$ & $46 \%$ & $30 \%$ & $36 \%$ & $43 \%$ & $28 \%$ & $29 \%$ \\
\hline Travel time & $35 \%$ & $25 \%$ & $40 \%$ & $42 \%$ & $31 \%$ & $27 \%$ & $44 \%$ & $29 \%$ & $27 \%$ \\
\hline $\begin{array}{c}\text { Crime at } \\
\text { ranks/termini } \\
\text { /station }\end{array}$ & $51 \%$ & $10 \%$ & $39 \%$ & $38 \%$ & $19 \%$ & $44 \%$ & $41 \%$ & $22 \%$ & $37 \%$ \\
\hline $\begin{array}{c}\text { Crime on } \\
\text { bus/train/taxi }\end{array}$ & $65 \%$ & $10 \%$ & $25 \%$ & $55 \%$ & $11 \%$ & 34 & $38 \%$ & $11 \%$ & 51 \\
\hline $\begin{array}{c}\text { Taxi } \\
\text { industry } \\
\text { violence }\end{array}$ & -31 & -20 & $49 \%$ & $30 \%$ & $11 \%$ & $59 \%$ & 20 & 31 & $49 \%$ \\
\hline $\begin{array}{c}\text { Safety from } \\
\text { accidents }\end{array}$ & $19 \%$ & $15 \%$ & $66 \%$ & $20 \%$ & $16 \%$ & $66 \%$ & $18 \%$ & $16 \%$ & $66 \%$ \\
\hline $\begin{array}{c}\text { Frequency } \\
\text { peak }\end{array}$ & $38 \%$ & $24 \%$ & $38 \%$ & $36 \%$ & $28 \%$ & $36 \%$ & $42 \%$ & $30 \%$ & $28 \%$ \\
\hline $\begin{array}{c}\text { Frequency } \\
\text { off-peak }\end{array}$ & $46 \%$ & $42 \%$ & $12 \%$ & $40 \%$ & $35 \%$ & $25 \%$ & $33 \%$ & $32 \%$ & $35 \%$ \\
\hline Punctuality & $50 \%$ & $29 \%$ & $21 \%$ & $46 \%$ & $25 \%$ & $29 \%$ & $45 \%$ & $17 \%$ & $38 \%$ \\
\hline $\begin{array}{c}\text { Facilities at } \\
\text { termini }\end{array}$ & $14 \%$ & $34 \%$ & $52 \%$ & $13 \%$ & $38 \%$ & $49 \%$ & $21 \%$ & $27 \%$ & $52 \%$ \\
\hline $\begin{array}{l}\text { Overall } \\
\text { quality }\end{array}$ & $37 \%$ & $20 \%$ & $43 \%$ & $33 \%$ & $20 \%$ & $47 \%$ & $33 \%$ & $24 \%$ & $43 \%$ \\
\hline
\end{tabular}

Source: Research Survey Findings, 2010. 
have high car ownership. This situation leads to the generation of traffic congestion spots and points along main routes and arterials linking such settlements (e.g. Thembisa, Orlando, Soweto) with major socio-economic locations and facilities in the metropolitan and urban areas (e.g. Sandton, Rosebank, Menlyn etc). Examples include the following off rumps along the N1 route, Witbank, Lynwood, Atterbury, Hans Strydom Drive, Delmas, Old Johannesburg Road, R21, John Vorster, Olifantsfontein to name a few examples. Further, a number of urban public transport initiatives such as the Gautrain Rapid rail link initiative and the Bus rapid Transit (BRT) have been embarked by the South African government to tackle the above mentioned transport challenges. However the extent to which such initiatives has contributed towards reversing the dysfunctional urban public transport system and route network in GJR is still largely a grey area.

\subsection{Public transport anatomy in the greater Johannesburg region}

Minibus-taxis are the dominant mode of public transport in GJR for approximately $72 \%$ of all public transport users (Lombard et al. [14]). These taxis do not operate according to timetables but utilize the concept of full loads. Routeing is highly structured by the taxi associations that assign operators specific routes or group of routes (1DP, 2008). The bus and metro services also serve the commuting public in the region. Trip interchange and transfers between taxis and bus, between taxi and train make and taxi-to-taxi transfers ("intramodalism") are a characteristic of the region transport structure. Most of the transfers occur in the CBD's of Pretoria, Sandton, Benoni, Midrand and Johannesburg major urban nodes. The average travel time to work for people using one taxi all the way is 30 minutes, and for those using a taxi-taxi combination is 78 minutes. Those using a taxi-taxi-taxi combination spend 99 minutes (Gauteng [15]). The highest travel times in CoJ are for those people using a taxi-train-taxi combination (115 minutes per one way journey), a taxitrain-train combination (133 minutes) or a taxi-bus-taxi combination (160 minutes) (Lombard et al. [15]). A taxi-bus combination gives a journey time average of 85 minutes, and taxi-train of 84 minutes. The National Travel Survey (2006) report by Statistics SA shows that South Africans who use their own vehicles spend at least $1 \frac{1}{2}$ hours in traffic each day, while 10 million people who use public transport spend 2 hours getting to and from work (Statistics South Africa, 2008). The need to alleviate traffic congestion and traffic decongestion could not be any greater (Chakwizira [4]). The spatial configuration of the GJR contributes much to the transport costs, adding to the problems of transfer delays between modes and lack of an integrated ticketing system.

Survey respondents from a limited purposive sample of randomised 300 residents from Soweto (100), Soshanguve (100) and Hammanskraal (100) conducted in 2010 expressed dissatisfaction with the taxi industry service. $60 \%$ of the respondents said they were dissatisfied with safety levels. This is lower than the $66 \%$ reported by the Gauteng Household Interview Survey of 2002 but is comparable. While during the Gauteng Household Interview Survey of 2002 $62 \%$ of the respondents were dissatisfied with facilities at taxi ranks, our 2010 
resident's interview survey recorded 60\%. During the Gauteng Household Interview Survey of $200257 \%$ of the respondents were dissatisfied with the levels of violence in the industry, our 2010 resident's interview survey recorded $51 \%$. Other causes of dissatisfaction such as crime at public transport ranks $(52 \%$ of users), cost (54\%), and frequency in the peak (44\%), frequency in the off-peak (41\%). In 2002 these other causes of dissatisfaction recorded the following statistics, crime at ranks (49\% of users), cost (48\%), and frequency in the peak $(38 \%)$, frequency in the off-peak $(35 \%)$. Overall, this is symptomatic of the dysfunctional public transport service levels in the metro bus and metro train services in the region (refer to Lombard et al. [14]). It is maybe because of some of these gaps that the Gautrain rapid rail link initiative and BRT Rea Vaya projects was developed as a measure to complement and upgrade the existing form of urban public transport options for travellers in the greater Johannesburg region. Nevertheless, the results of our 2010 residents' interview survey (although using a limited purposive randomised sample) corroborated the findings of previous extensive and larger non-purposive sample based Gauteng Household Interview Survey 2002 and National Household Transport Surveys (2003) by the Department of Transport. From this analysis, one could argue that the implementation of the Gautrain rapid rail link initiative and BRT Rea Vaya should contribute towards lowering levels of dissatisfaction and reversing dysfunctional challenges associated with urban public transport systems in South Africa.

An interesting urban public transport indicator of failure to cope with demand is that generalised costs of public transport have been on the increase (Statistics South Africa, 2008). Even for $20 \%$ of households with the lowest income, transport expenditure as a proportion of total household expenditure increased from $4 \%$ in 1995 to $10.6 \%$ in $2005 / 2006$. In terms of travel time, Lombard et al. [14] present that as a result of roadway congestion; many commuters have changed departure times to work to either earlier or later than traditional peak. Given, these multiple forms of dysfunctional urban public transport it is critical to find innovative ways to resolve the challenges.

\subsection{Urban commuter public transport interventions in the greater Johannesburg region: the Gautrain rail rapid link initiative}

Historically, land development in GJR has, in most cases, not been supported by an efficient public transportation system. This created the need to provide a supportive public transportation system to assist in optimising land use development, minimising congestion on the roads, reducing the number of road accidents and decreasing pollution levels, as well as moving towards the more holistic provision of an integrated transport system that includes public transport (Uys [17]). The Gautrain rapid rail link aims to contribute towards the realisation of these goals.

The Gautrain rail link entail a modern, state-of-the-art rail connection linking Pretoria, Johannesburg and OR Tambo International Airport. The network will consist of two spines: one linking Johannesburg and Pretoria, and the other linking Sandton and OR Tambo International Airport. A network length of 
approximately $80 \mathrm{~km}$ is planned, with provision for future extensions. Three anchor stations are proposed at Pretoria station, Johannesburg Park Station and OR Tambo International Airport (ORTIA), with seven other stations proposed at Hatfield, Centurion, Midrand, Marlboro, Sandton, Rosebank and Kempton Park (Rhodesfield). The train is expected to cut the number of cars on the N1 Ben Schoeman Highway by $20 \%$, or 135000 passenger trips per day by 2010 . However, figures released by Gauteng provincial government in 2003 indicate that project will do little to alleviate traffic on the over-used Ben Schoeman highway, as traffic volumes will be higher when Gautrain is completed and operating at full capacity. One argument is that a single lane cannot solve GJR urban public transport challenges.

The CoJ has implemented the Rea Vaya BRT system as a supporting solution for Johannesburg's congested roads and transport problems. The Rea Vaya BRT has all the benefits of a full train system going through the suburbs of Pretoria and Johannesburg in addition to flexibility and cost advantages of road transport. The Rea Vaya BRT comprises of a middle lane for large, high tech buses designed to transport commuters comfortably and quickly around Johannesburg. The system uses specific designated routes, enclosed bus stations along the routes and a high tech control centre. The Rea Vaya BRT urban transport network is designed to feed into and complement existing networks to ensure the most effective movement of people across the city. This ensures no competition with other transport systems such as Metrorail or the Gautrain. This BRT initiative forecloses that the Gautrain rapid rail link is not a panacea for urban public transport challenges in the GJR. The solution lies in implementing a package of interventions all meant to better urban public transport delivery and performance levels.

\section{Conclusions and recommendations}

This article confirms that conceptually public transport interventions such as the Gautrain and by extension the Rea Vaya Bus Rapid Transit have great potential in addressing urban public transport challenges for commuting communities. However, progress is constrained by the lack of a critical mass of urban transportation experts and professionals in South Africa. Consequently, overcoming the challenges of strongly fusing land use and transport development planning in the GJR of South Africa can be achieved by implementing a raft of interventions such as land densification, road pricing and car restraint measures, road expansion and construction applications. The major issues and recommendations emanating from this article are namely;

- The existing alignment, spatial configuration and functional pathways of Gautrain rapid rail link initiative route reinforce existing geographical fragmented and dysfunctional economic routes and corridor service delivery architecture. This consolidates inherited geographical dysfunctional spatial accessibility and mobility challenges in urban areas of GJR and requires implementation of innovative solution to reverse the trend. 
- Urban public transport initiatives should be inclusive and comprehensive in addressing the full life cycle dimensions of urban public transport challenges cutting across industry sectors and different divides in a society if the initiatives are to be sustainable.

- The Gautrain route needs extension and future plans should find an optimal mix of integrating the current north - south axis with an east west configuration where GJR growth is happening.

- Prospecting the feasibility of developing an underground/subway urban public transportation system and trams/light rail urban public transport systems in GJR is an option open for exploration.

- Utilising more efficient urban public transport modes in an age of dwindling oil and increased environmental consciousness is critical for South Africa given the MDGs, linking transport and climate change mitigation and adaptation measures post the Copenhagen Earth Summit.

This article has presented that urban public transport challenges in GJR of South Africa and by extension developing countries generally still remain a daunting task owing to a dysfunctional land use and transport base/structure. However, adopting integrative and collaborative approaches provides opportunities for reversing the dysfunctional structures to be succeeded by a next generation of structurally efficient land use and sustainable transport systems.

\section{References}

[1] Thomlinson R et al (2003) Emerging Johannesburg : Perspectives On The Post-Apartheid City, Routledge, New York, London ISBN 0-415-93558-X

[2] Department of Transport (2007a) Public Transport Strategy. Public Transport Action Plans and 2010 documents. Pretoria South Africa

[3] Beavon K (2004) Johannesburg - The Making And Shaping Of The City, Unisa Press, University of South Africa ISBN 1-86888-303-5

[4] Chakwizira J (2007) The Question of Traffic Congestion and Decongestion in the Greater Johannesburg Region, 26th Annual Southern African Transport Conference and Exhibition, Pretoria, South Africa, 9-12 July 2007, pp 13, ISBN : $192001702 X$

[5] Department of Transport (2007b) Public Transport Action Plan. Phase 1 (2007-2010) Catalytic Integrated Rapid Public Transport Network Projects. Public Transport Action Plans and 2010 documents. Pretoria, South Africa

[6] Chakwizira J, Mathetha M, Mashiri M, Marrian B (2009) Sustainable Public Transport Overview Report, South African Cities Network, Braamfontein, Johannesburg, South Africa

[7] Cervero, R. (1998). The transit metropolis - a global enquiry. Island Press, Washington

[8] Wright, L. (2005). Bus Rapid Transit. In: GTZ Sustainable Transport: A sourcebook for policy-makers in developing cities, Eschborn: GTZ 
748 Sustainable Development and Planning V

[9] Gwilliam, K. (2002). Cities on the move: a World Bank urban transport strategy review. The International Bank for Reconstruction and Development / The World Bank, 1818 H Street, NW Washington, DC 20433

[10] Shaw A (2005) Public Transport: Gautrain Can Show Way For SA, Business Day Final 05 September 2005 page 11

[11] (2008) Johannesburg Integrated Development Plan, Johannesburg, South Africa

[12] Chakwizira J, Mashiri M (2008) The role of transport governance in socioeconomic development in South Africa, Sustainable Transport: 28th Annual Southern African Transport Conference (SATC) 2009, Pretoria, South Africa, 6-9 July 2009, pp 1-18 ISBN: 9781920017392

[13] Donaldson R. (2006). Mass rapid rail development in South Africa's metropolitan core: Towards a new urban form? Land Use Policy 23: 344-352

[14] Lombard, M. Cameron, B. Mokonyama, M. Shaw, A. (2007). Report on trends in passenger transport in South Africa. Development Bank of Southern Africa, South Africa. ISBN: 1-919692-95-9

[15] Gauteng. (2002). Gauteng household travel survey data, obtained from the City of Johannesburg, City of Johannesburg, South Africa

[16] Statistics South Africa. (2008). Income and expenditure of households 2005/2006: Analysis of results. Statistics South Africa, Pretoria. ISBN No. 978-0-621-37635-7

[17] Uys, T. (2006). 'Not in my Backyard?': Challenges in the Social Impact Assessment of the Gautrain Rapid Rail Link Project in South Africa, Department of Sociology, Rand Afrikaans University, Auckland Park 